\title{
Mi testimonio: Recuerdos en lontananza
}

\author{
Dr. RICARDO SONNEBORN G. ${ }^{1}$
}

1 Hospital del Trabajador de Santiago, Chile.

\section{My testimony. Distant memories}

Permítanme expresar mis sinceros agradecimientos a todos quienes han hecho posible tan importante distinción. Sin duda, la mayor a que puede aspirar un cirujano y el título máximo que otorga esta Sociedad. Emocionado, lo recibo con inmensa alegría, pero al mismo tiempo, con mucha humildad y profundo respeto. Deslumbrado, me asomo a la galería de figuras ilustres e insignes maestros de la cirugía chilena que me han precedido, y con los que vuestra benevolencia ha estimado homologarme. Conmovido, retribuyo también numerosas muestras de consideración y afecto.

Resulta de nobleza indispensable, compartir esta distinción con mi familia, mi núcleo más íntimo y querido, un verdadero puntal y permanente fuente de inspiración y respaldo. Sin ellos, mi vida no habría tenido el mismo sentido. Percibiendo la importancia de este acto, y con ese gran corazón que los caracteriza, hoy están todos aquí. También, nuestros adorables nietos. Ellos son una alegría constante. Igualmente, agradezco el inmenso cariño de familiares, colegas y amigos, que con fina deferencia han estimado estar presentes. Un recuerdo especial para mis padres, que ya no están, ellos son parte importante de los logros y merecen compartir el regocijo.

Han escuchado una muy generosa reseña biográfica. Vaya mi especial reconocimiento al Dr. Froilán Fernández por el esfuerzo, y sobre todo por su tan emotivo gesto de amistad. El cariño y la lealtad nos han unido por muchos años. A diario, hemos compartido la tarea quirúrgica, científica y académica.

Sin el afán de desmerecer la solemnidad de la ocasión y menos aún del alto honor que se me confiere, he estimado desechar cavilaciones profundas y disquisiciones metafísicas, y orientar mis palabras a hilvanar algunas reflexiones, hurgar someramente en los recuerdos y rescatar algunos jirones pintorescos y anecdóticos, ilustrativos de aspectos humanos y el camino recorrido.

La leyenda de la vida se teje desde el inicio y se va conformando de interminables detalles. Somos el resultado de enseñanzas, influencias y experiencias. Nací y me crié en un hogar de raigambre europea. Mucho cariño... y también disciplina. Demostró ser buena escuela. Se la traspasé a mis hijos, quienes a pesar de encontrarme "un poco cuadrado", hoy se rigen por el mismo esquema.

Postulé a Medicina en la Universidad de Concepción. Esa fría mañana, llegado de Santiago en el "tren nocturno", entonces el medio habitual de viaje, crucé raudo a iniciar los trámites. Un Profesor me entrevistó, preguntándome por 3 caracteres distintivos de la Plaza de Armas de la ciudad. Enmudecí. Él me sacó de mi estupor, indicando que allí, en 1818, en acto solemne, Bernardo O'Higgins declaró la Independencia de Chile; que estaba plantada con tilos y que en la columna central de su fuente tiene impreso el escudo chileno. Pero, el orfebre inglés confundió el huemul con un león heráldico, y le puso cola. Mi supina ignorancia no fue impedimento y fui aceptado. Una época de entrañables recuerdos, en una ciudad universitaria por excelencia.

Al inicio de los ramos clínicos me trasladé a Santiago. Llegué al Hospital San Borja, a la Cátedra del Profesor Roberto Estévez Cordovez, hombre fino, culto y distinguido. Gran lector y estudioso, dominaba el latín y griego. Muy tempranamente, junto al Dr. Sergio Olmedo y al Jefe de Clínica, Dr. Hernán Castro Möller, nos traspasó toda la tarea docente de la entonces llamada Cátedra. Pronto cambiaría la estructura. Era la época de la Reforma Universitaria.

Albert Schweitzer decía: "siempre y en todo lugar, hay que buscar hacer el bien. Cada hombre debe escrutarse y descubrir su real valía. Uno, debe entregar al menos una parte de su tiempo a sus semejantes, prodigando aunque sea una pequeña acción al necesitado, sin esperar recompensa, sino tan sólo por el privilegio de hacerlo. No transitamos solos por el mundo. Nuestros hermanos también están aquí...". Esta imagen se encarnaba vivamente en la personalidad del Dr. Marcos Vergara Letelier, ex Presidente de esta Sociedad, mi Maestro en la Ciru- 
gía. Me entregó conocimientos, pero por encima de todo, virtudes humanas. Me traspasó su inagotable espíritu de comprensión, servicio y solidaridad. El Servicio de Cirugía, funcionaba entonces en vetustos Pabellones construidos en 1886, por la epidemia de cólera. En aquellas interminables salas, a menudo lo encontré sentado a la orilla de una cama, cuchara en mano, alimentando a esa paciente debilitada, incapaz de valerse por si sola. Luego, en sucesivas y más modernas dependencias, desarrollé cirugía y docencia hasta 1980.

En la Asistencia Pública viví una época memorable. Era el "Servicio Militar", obligatorio en el inicio de todo cirujano. Entonces, la "Escuela de Urgencias". En esa época su figura señera era el Dr. Emilio Salinas Donoso, Maestro de la Cirugía Chilena (1979). Aprendíamos del talento y experiencia de los mayores. Los diagnósticos se hacían sobre una base eminentemente clínica. A juzgar por los resultados, los errores eran escasos. En mis inicios, mi jefe, hoy querido amigo, Dr. Antonio Yuri, me ungió "apendicectomizador oficial" del turno, un título casi nobiliario. En los breves turnos de aquel entonces, operaba 3 a 4 pacientes. Luego, allí pasé a la UTI, una de las primeras en el sistema estatal. En un reducto tradicional de internistas un cirujano era "ave rara". Recién aparecían los respiradores "de presión", el manejo hemodinámico del shock, el equilibrio ácido-básico, la diálisis peritoneal y asomaban rudimentarios ecógrafos. Artesanalmente, con sondas de colédoco, confeccionábamos dispositivos para medir presión venosa central. El 11 de Septiembre, bruscamente me gradué como"cirujano de guerra". Comprobé la mentada letalidad de las heridas por proyectiles de alta velocidad. En menos de 24 horas, operé 7 y asistí al Dr. Enrique Ceroni en la cirugía de otros 4 traumatismos vasculares, con excelente resultado y sin mortalidad.

En 1970, a través de la OMS, accedí a una de 3 becas mundiales de Cirugía Cardiovascular, de la Swedish National Association against Heart and Chest Diseases, que dirigía la reina sueca. En la Clínica de Tórax del Hospital Karolinska en Estocolmo, el jefe y hasta entonces máxima figura, era el Dr. Clarence Craaford, pionero en el desarrollo de la circulación extracorpórea, médico personal y compañero de cacería del Rey Gustavo Adolfo. Las latitudes escandinavas son reconocidos Centros de Investigación, reputados por rigurosa base fisiopatológica, estudios prolijos, cuidadosa selección de pacientes y depurada cirugía. Junto con mi Jefe, Dr. Stig Ekeström, a diario emprendíamos diversos procedimientos de revascularización arterial, con minuciosas mediciones de parámetros fisiológicos. Una visión pionera, precursora de los Laboratorios Vasculares, hoy una rutina en todo el mundo. Ese
10 de Diciembre, tuve el privilegio de asistir a la Ceremonia de entrega de los Premios Nobel.

En 1971, en Helsingborg, sur de Suecia, a orillas del Mar del Norte, y enfrente al "Castillo de Hamlet", en el Congreso Europeo de Cirugía Experimental, conocí al Dr. Erwin Hirsch, cirujano norteamericano, que regresaba de cumplir una estada en la base de Danang, en Vietnam. Surgió una amistad fraterna y duradera. En latitudes y realidades diferentes, a lo largo de los años, compartimos la pasión por las Urgencias y el Trauma. A partir de 1985, nuestra relación y camino convergen fuertemente, al confiarnos el American College of Surgeons, por su intermedio, el Curso ATLS, referido a "Manejo Inicial en Trauma". Junto a él y con el Dr. Froilán Fernández, instauramos dicho Programa en Chile, Argentina, Brasil, Perú y Bolivia. Con el respaldo de nuestras sociedades científicas quirúrgicas, y la activa participación de muchos colegas, a quienes agradezco su infatigable apoyo, esta iniciativa se hizo realidad. Apareció como una respuesta tangible a la catastrófica multitud de accidentados e imponente cifra de muertos, heridos y secuelados. Ha salvado muchas vidas, pero paradojalmente no la del propio Dr. Hirsch. Sus días terminaron trágicamente en Mayo de 2008, cuando sin chaleco salvavidas, su frágil bote volcara en las gélidas aguas de la bahía de Maine, frente a Boston.

El Trauma ha sido un "leitmotiv". Antes una expresión peregrina de pocos y vaga para muchos. Con el advenimiento del Programa ATLS, adquirió significado y un inusitado vigor. Se posicionó como especialidad. Ha incorporado a cirujanos de todas las especialidades. También anestesiólogos e intensivistas. Introdujo el uso rutinario de tablas espinales, collares cervicales, cánulas para vía aérea, etc; dispositivos y técnicas hoy obligatorias en la atención de urgencias y diaria imagen televisiva. Es motivo de estudio y presencia en Cursos, Congresos y Publicaciones. Chile, hoy con orgullo exhibe cifras de éxito terapéutico comparables a Centros de Trauma del mejor nivel. Y, nuestros especialistas, son destacados exponentes a nivel local e internacional.

A partir de 1964 inicié mi vínculo con la ACHS. El año 1980, llegué al Hospital del Trabajador, mi casa actual. Una institución privada, ricamente dotada, con férrea disciplina y cuyo quehacer, logros y prestigio están sólidamente cimentados. Me encomendaron formar el Servicio de Cirugía. Con la incorporación y aplicación plena y rutinaria de conceptos ATLS y trabajo en equipo, se ha erigido formalmente en un Centro de Trauma, y posicionado en inmejorable nivel. En atención de Politraumatizados, exhibe una mortalidad de $8 \%$, que compara muy favorablemente con el 6 a $10 \%$, aceptado para Centros de Nivel I en Estados Unidos. 
Tuve el privilegio de acceder a la Presidencia de las dos sociedades quirúrgicas chilenas, y en una de ellas, el American College of Surgeons, ocupé el cargo de Gobernador. En los eventos de ambas, he sido invitado habitual al Programa Científico. Una experiencia gratificante que agradezco y valoro. Me ha permitido conocer y cultivar la amistad de muchos colegas.

Por último, y en otra dimensión, destaco el tiempo compartido con actividades agrícolas, a cargo de mi esposa. Y como médico de KLM. Por largos años, nos permitió soñar con los lugares más recónditos, y efectivamente viajar y visitarlos.

A juzgar por este reconocimiento, nuestro accionar tuvo una repercusión positiva y las enseñanzas no cayeron en el vacío. Mi norte siempre fue crecer y desarrollarme. Acorde al Papa Benedicto XVI: "El afán de superación está en la naturaleza de cada ser humano". En un trabajo con clara connotación social entregué a pacientes, colegas y estudiantes lo mejor de mí. La perjudicada, nítidamente ha sido mi familia. Más de alguna celebración familiar o acto en el colegio de nuestros hijos, me encontró operando alguna urgencia. Ellos, con inmensa bondad supieron comprender. Pero, yo resiento ese vacío. Ahora, aprendida la lección, estoy compensando a los nietos.

A nuestro juicio, el pasado constituye sólo una referencia. Un cúmulo de vivencias e imágenes, algunas lejanas, a veces borrosas y polvorientas, arrumbadas en el "baúl de los recuerdos". Porque lo importante es el soplo vital, la llama que se aviva cada día. El imperativo es tener un objetivo para emprender cada jornada. Vivir intensamente los desafíos del presente y seguir atisbando el futuro con optimismo e ilusión. Pero, rescato un singular recuerdo familiar. En la Primera Guerra Mundial, mi abuelo materno, soldado alemán, en una trinchera, de pronto tropieza con un contrincante francés. Era matar o morir. Por un instante se miran a los ojos. Deponen las armas. Se estrechan en un abrazo, intercambian direcciones y luego correspondencia hasta el fin de sus días.
La vida, como el ejercicio de la Medicina se nutre "día a día". En nuestros comienzos, los maestros nos enseñaban: "los viejos sobre 40 años...". No ha transcurrido tanto tiempo, pero todo ha cambiado vertiginosamente. Ese horizonte antes distante, hoy apenas constituye el inicio de la madurez plena. Sin darme cuenta he llegado a la edad mayor. "Sí, sí, todos queremos llegar a viejos..." declamaba Francisco de Quevedo. Una quimera que sólo pocos alcanzan. La ocasión es propicia para tornar la vista y hacer un balance. Con inmensa satisfacción, admito que la realidad ha superado con largueza las mejores expectativas. A pesar de un trajín intenso, el recorrido ha sido grato. Un privilegio inmenso desarrollarme y desempeñarme en una actividad profesional que me ha llenado el gusto. Los eventuales esfuerzos y sacrificios han sido algo natural. Y el entusiasmo permanece incólume.

En una época, cuando el cuerpo, la mente y los sentidos comienzan a flaquear, Dios me ha prodigado el mayor de los dones, al permitir presentarme ante Uds. con buena salud y mente clara. Para lo que viene, por encima de todo y mi motivo principal: anhelo brindarme a mi querida familia, que tan generosa ha sido. A ellos les debo mucho, especialmente tiempo. Si, tiempo para estar juntos y disfrutar. A familiares y amigos, la oportunidad de compartir, divagar y "hablar de cualquier cosa". Luego de tantos años de laboriosidad trascendente: "aprender a perder el tiempo". Ojalá, tener salud y mantener un espíritu positivo, alegre y emprendedor. "Que el sol siga dando calor y energía a mi cuerpo y la luz ilumine mi mente. Que el alma siga cultivando afectos, la rectitud sea la norma y la solidaridad mi fuente de inspiración". En suma, "Mantener encendida la llama" y tener "algo porqué vivir". Que sigan existiendo, y la memoria atesore, momentos tan significativos. En consonancia con García Márquez: "la muerte no llega con la vejez, sino con el olvido...".

Muchas Gracias.

La Serena, $1^{\circ}$ de Diciembre de 2009. 